\title{
Burst-Swimming Performance of Larval Zebra Danios and the Effects of Diel Temperature Fluctuations
}

\author{
LeE A. Fuiman \\ School of Natural Resources, S. T. Dana Building, University of Michigan \\ Ann Arbor, Michigan 48109, USA
}

\begin{abstract}
Zebra danios Danio [Brachydanio] rerio were spawned and their eggs and larvae were reared in a simulated natural thermal regime, increasing from 21 to $30^{\circ} \mathrm{C}$ for $7 \mathrm{~h}$ and decreasing to $21^{\circ} \mathrm{C}$ for $17 \mathrm{~h}$, daily. Burst-swimming performance was provoked by electrical stimulation of larvae (mean total length $=3.6 \mathrm{~mm}$ ). Responses were filmed at $400 \mathrm{frames} / \mathrm{s}$ at temperature intervals of $3^{\circ} \mathrm{C}$. Distance travelled in a specified time $\left(S_{x}\right)$, maximum velocity, and maximum acceleration increased with temperature. Size-specific maximum velocity was considerably higher than previously reported for larvae. A predictive model relating $S_{t}$ to temperature was developed. In theory, the observed effects of temperature could have been due to changes in physiological rates or in water viscosity, but Reynolds numbers were too high for a substantial viscosity effect. The $\mathrm{Q}_{10}$ for $S_{t}$ was 1.6 , that for maximum velocity was 1.4 . Results suggest that, other factors being equal, larvae are potentially more vulnerable to predation at sunrise or at other times when water temperature is low.
\end{abstract}

Many kinds of larval fishes, especially those of freshwater species, reside in shallow, often peripheral, habitats where temperature fluctuates widely. Such changes may be sudden or gradual, predictable or random, natural or anthropogenic. The temperature of littoral habitats of lakes and ponds, and backwater areas of streams and rivers, varies widely and predictably as a result of insolation and poor mixing. Cloud cover, precipitation, and other meteorological processes can modify the "usual" thermal regime. Diel temperature fluctuations typically range from 5 to $15^{\circ} \mathrm{C}$ (Bamforth 1962; Smid and Priban 1978; Caulton 1982) in the summer and may reach as much as $20^{\circ} \mathrm{C}$ (D. L. Soltz, personal communication). Average rates of heating are between 1 and $2.5^{\circ} \mathrm{C} / \mathrm{h}$ (Elliott 1981). Larvae are largely confined to these areas of thermal fluctuation because of their poor motility in comparison to the size of the affected habitat. Consequently, they experience temperature fluctuations that may constrain their activities.

Larvae use burst swimming for critical (life-preserving) activities such as food capture and predator evasion. Foraging and migration result from routine or steady swimming. Temperature changes could affect swimming performance through their influences on the physical properties of water and on a larva's physiological processes $\left(Q_{10}\right.$ effects; $\mathrm{Q}_{10}$ is the factor by which a rate changes with a $10^{\circ} \mathrm{C}$ change of temperature). Physiologically, rates of processes such as nerve-impulse transmission and muscle-fiber contraction increase with temperature. Webb (1978) showed that burst-swimming performance in subadult rainbow trout $\mathrm{Sal}$ - mo gairdneri was better at higher temperatures than at lower ones.

Water viscosity is potentially important to swimming larvae. When animals move through fluids they are subject to forces arising from inertial and viscous effects. The ratio of these effects is expressed as the Reynolds number $(R e)$, such that

$$
R e=U L \rho \mu^{-1}
$$

where $U$ and $L$ are the velocity and length of the larva, and $\rho$ and $\mu$ are density and viscosity of the fluid, respectively. The small values for $U$ and $L$ of a larva contribute to a low $\operatorname{Re}$. At low $\operatorname{Re}(<10$ 20 ), viscous forces dominate and inertial effects are negligible (Blaxter 1986, this issue; Webb and Weihs 1986, this issue); total drag is proportional to viscosity. Water viscosity changes appreciably with temperature, more so at colder temperatures than at warmer ones. Density remains nearly constant. For a change from 20 to $30^{\circ} \mathrm{C}$, for example, viscosity decreases by more than $25 \%$. Consequently, the total drag acting on a larva experiencing low Reynolds numbers would be $25 \%$ less at $30^{\circ} \mathrm{C}$ than at $20^{\circ} \mathrm{C}$. However, Webb and Weihs (1986) suggest that during burst swimming larvae are not so affected by viscous forces because they exceed the low Reynolds number regime. Yet, the initial and final stages of a burst response involve low velocities and are therefore described by low Reynolds numbers. Changes in viscosity should modify performance during these portions of the response.

Observations that habitats occupied by larvae 
are subject to common temperature fluctuations, combined with evidence that temperature should affect a larva's physiology and swimming environment, led me to develop and test the following hypothesis: typical diel temperature fluctuations significantly influence burst-swimming performance of fish larvae. The importance of such an effect arises because larvae use burst swimming during critical activities.

\section{Methods}

A natural thermal regime was established in an aquarium to simulate the conditions of the littoral zone of a pond during summer (Smid and Priban 1978). An electric heating element was immersed in the $60-\mathrm{L}$, glass aquarium and a timer limited heating to the hours between 0700 and 1400 . Room temperature was maintained at $20^{\circ} \mathrm{C}$ and acted as the cooling mechanism for the aquarium. A rheostatic control on the heating element was set so that the diel cycle ranged from 21 to $30^{\circ} \mathrm{C}$, heating for $7 \mathrm{~h}$ and cooling for $17 \mathrm{~h}$. Illumination was provided between 0700 and 2100 hours. Temperature was measured with a mercury thermometer graduated in $0.1^{\circ} \mathrm{C}$ increments. Experiments were performed on larval zebra danios Danio [Brachydanio] rerio, ${ }^{1}$ an Asian cyprinid for which there is a large body of literature on morphogenesis and development of the startle response (Laale 1977; Eaton and Nissanov 1985; Eaton 1986, this issue). A pair of adults was spawned and their eggs and larvae were reared in the fluctuating thermal regime. Once larvae began to swim up (yolk-bearing, mean total length $3.6 \mathrm{~mm}$ ) 20 individuals were placed in a water-filled arena $(50 \times 50 \times 15 \mathrm{~cm})$ with opaque plastic sides and plate glass top and bottom. A solid wire electrode spanned the length of two opposing sides of the arena. Larvae were stimulated to maximal burst performance with an $8.6-\mathrm{V} / \mathrm{cm}$ direct current. Responses of larvae were recorded on cinefilm (Tri-X reversal, ASA 200) at a rate of 400 frames/s. During filming, light from a quartz lamp passed through the aquarium (serving as a heat sink) then a polarizing filter and the arena. The camera was located above the aquarium and fitted with a $50-\mathrm{mm}$ macro lens. A neon bulb adjacent to the arena signalled the stimulus. Filming sequences were scheduled to coincide with $3^{\circ} \mathrm{C}$ changes in temperature (in the following order, $30,27,24,21,24,27$, and $30^{\circ} \mathrm{C}$ ) during a $24-\mathrm{h}$

\footnotetext{
${ }^{1}$ This species is currently placed in the genus Danio (Jayaram 1981), although it is usually associated with Brachydanio.
}

period. Larvae remained in the arena for the duration of the experiment. The arena was partly immersed in the covered aquarium between filming sequences to ensure the appropriate temperature within.

Films were projected (enlarged $9 \times$ actual size) and analyzed frame by frame. Fish that failed to show a startle response, the stereotypical behavior pattern that initiates burst swimming (Eaton et al. 1977), or whose early portion of a response was hindered by a wall of the arena or another fish were not analyzed. Swimming performance is most accurately measured for the movement of the center of mass, the point about which propulsive forces are resolved. Points away from the center of mass have a considerable yaw (Batty 1981) and therefore overestimate distances travelled. The center of mass is difficult to assess in larvae. Instead, I used a point on the dorsal midline immediately behind the eyes, which was probably a reasonably close estimate. Tracings of the progressive displacement of this point were sent as Cartesian coordinates from a sonic digitizer to a computer. Straight line distances between consecutive positions were proportional to the average velocities between those points. These values were "smoothed" by calculating five-point moving averages to compensate for the yaw resulting from the error in approximating the center of mass, as well as errors in tracing and digitizing. Accelerations were calculated as the differences between consecutive, smoothed velocity values (that is, changes in velocity per frame, and hence, time). Statistical decisions were made at the $(\alpha=) 0.05$ level of significance.

\section{Results}

In all, 102 responses were analyzed; there were 11 to 18 responses in each sequence. Larvae were always motionless at the onset of the stimulus. During a response, velocity increased rapidly from zero towards a maximum, fluctuated about this value for a period (Figure 1), then decreased to zero. In several instances the latter portion of a response was curtailed by collision with a wall. Consequently, I present no information on duration of response or total distance travelled.

The simplest measure of burst-swimming performance is distance travelled in a specified time, a reflection of mean velocity (Webb 1978). This measure, $S_{t}$, correlated positively with temperature, $T$ (Figure 2). Least-squares estimates of slopes for this relationship consistently increased with elapsed time for 10 regressions on elapsed times 


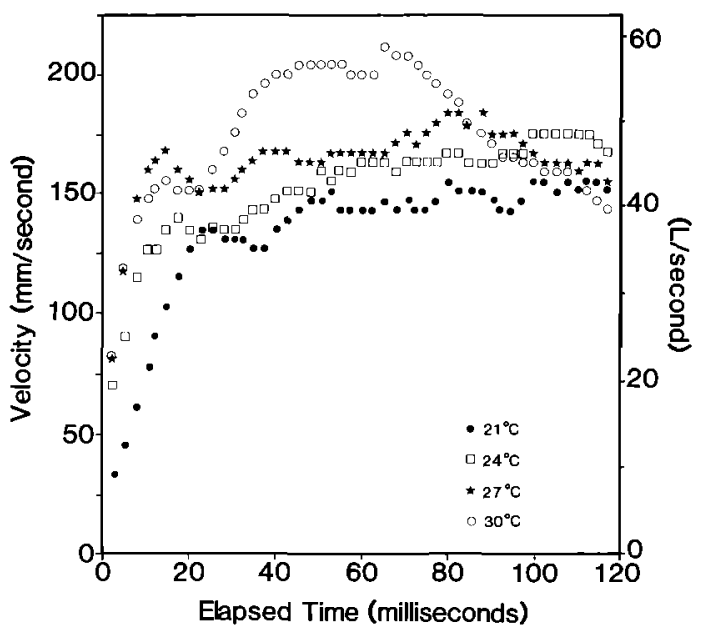

FIGURE 1.-Mean velocities of zebra danios (in $\mathrm{mm} / \mathrm{s}$ and body lengths $\mathrm{L} / \mathrm{s}$ ) during burst-swimming responses at four temperatures. Observations were curtailed at $120 \mathrm{~ms}$. Replicates at 24,27 , and $30^{\circ} \mathrm{C}$ were combined despite small differences in temperature.

between 20 and $200 \mathrm{~ms}$ ( $20-\mathrm{ms}$ increments). No intercepts were significantly different from zero. Therefore, new estimates for slopes relating $S_{t}$ to $T$ were calculated by forcing the regressions through the origin (Snedecor and Cochran 1967). The resultant equation can be used to determine the slope for any $t$ (in milliseconds):

$$
\text { slope }=-0.0806+0.0069 t ; \quad r^{2}=0.9995 \text {. }
$$

Because the intercept for the relationship between $S_{t}$ and $T$ is zero,

$$
S_{t}=T(-0.0806+0.0069 t)
$$

$S_{t}$ is measured in $\mathrm{mm}$ and $T$ in ${ }^{\circ} \mathrm{C}$. Residuals (differences between observed and predicted $S_{t}$ ) were homogeneous with respect to both temperature and elapsed time; the SD was $2.03 \mathrm{~mm}$ based on 6,762 points.

Temperature also affected instantaneous velocity and acceleration. Larvae at higher temperatures accelerated more rapidly during the first 10 to $15 \mathrm{~ms}$ (four to six frames) than when in colder water. This resulted in higher maximum velocities (Figures 1, 3). Mean size-specific maximum velocity ranged from 50 to 66 body lengths per second $(\mathrm{BL} / \mathrm{s})$. This is considerably greater than the $10-\mathrm{BL} / \mathrm{s}$ "rule of thumb" for burst-swimming larvae (Blaxter 1969), and is only partly a result of the greater accuracy rendered by the high framing rate used here (Eaton et al. 1977).

Maximum velocity during a burst response was

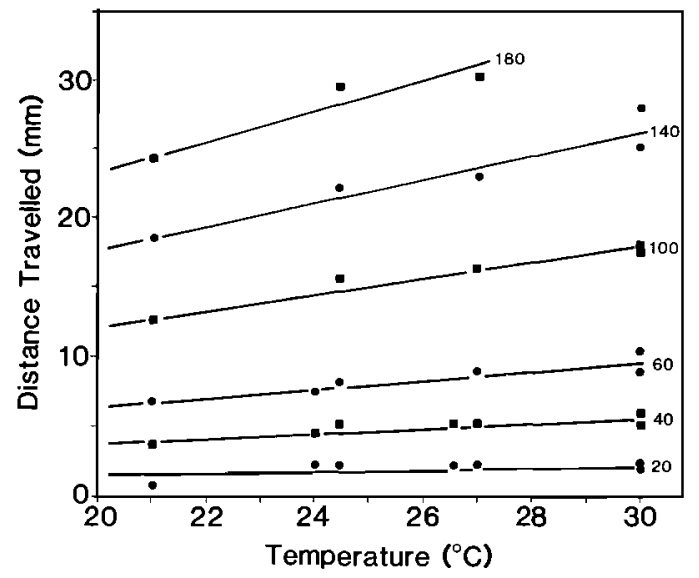

FIGURE 2.-Relationships between distance travelled $\left(S_{t}\right)$ by zebra danios and temperature for specified periods of elapsed time. Regression lines pass through the origin. Numbers at right indicated elapsed time in milliseconds.

directly related to temperature (Figure 3, Table 1). However, the values obtained at 27 and at $30^{\circ} \mathrm{C}$ during the heating phase of the thermal regime were significantly lower than those during the cooling phase. Variances were virtually identical for the four sequences filmed during the cooling phase. Those from the heating phase were higher. The cause oî the discrepancies between heating- and cooling-phase measures of maximum velocity is unknown. The lower maximum velocities during

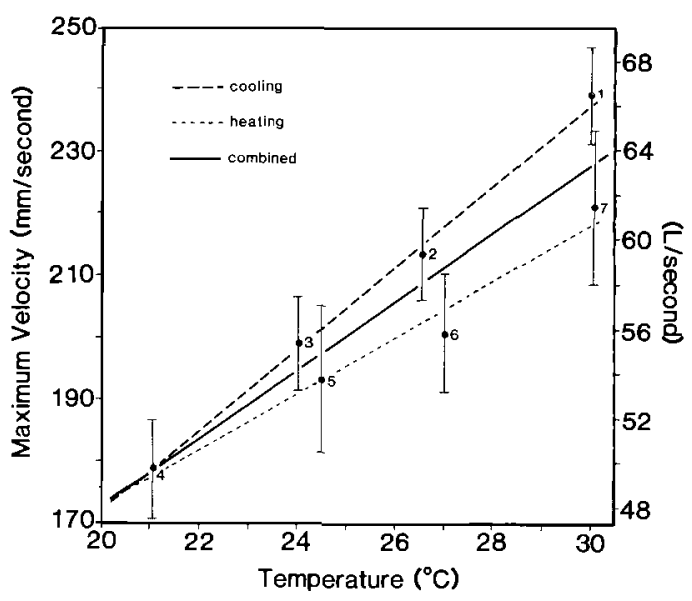

Figure 3. - Relationship between maximum velocity of zebra danios (in $\mathrm{mm} / \mathrm{s}$ and body lengths $\mathrm{L} / \mathrm{s}$ ) and temperature. Means $\pm 2 \mathrm{SE}$ are plotted. Numbers indicate the temporal sequence of responses $(1-4$, cooling phase; 4-7, heating phase). 
TABLE 1.-Regression statistics for the relationships between maximum velocity and temperature for zebra danios (Figure 3). Sequence $4\left(21^{\circ} \mathrm{C}\right)$ was included in all regressions.

\begin{tabular}{lcccc}
\hline Regression & Slope & Intercept & $\begin{array}{c}\text { Corre- } \\
\text { lation }\end{array}$ & $\begin{array}{c}\text { Number } \\
\text { of obser- } \\
\text { vations }\end{array}$ \\
\hline Cooling phase & 6.60 & 40.21 & 0.823 & 56 \\
Heating phase & 4.54 & 82.22 & 0.785 & 59 \\
Combined data & 5.33 & 67.01 & 0.652 & 102 \\
\hline
\end{tabular}

heating may have resulted from incomplete acclimation during this period of rapid temperature change $\left(1.3^{\circ} \mathrm{C} / \mathrm{h}\right.$ versus $0.5^{\circ} \mathrm{C} / \mathrm{h}$ during cooling). Thermal inertia might be ruled out because of the small size of the larvae and the low heating rate. Lower velocities and increased variances observed in the last two filming sequences suggest that larvae became fatigued or stressed. There were no outward signs of stress in the larvae at the end of the experiment, and the interval between shocks ( $\geq 65$ $\mathrm{min}$ ) would have permitted adequate time for recovery. Larvae were still using endogenous nutrition, so starvation was not a problem.

Maximum acceleration during a burst showed a local maximum near $27^{\circ} \mathrm{C}$ (Figure 4). Mean values at 27 and at $30^{\circ} \mathrm{C}$ did not differ significantly between the heating and cooling phases. However, there was a significant difference at $24^{\circ} \mathrm{C}$.

\section{Discussion}

The effects of the simulated natural thermal regime on burst-swimming performance were likely physiological. Over the experimental temperature range $\left(21\right.$ to $\left.30^{\circ} \mathrm{C}\right), S_{t}$ had a $\mathrm{Q}_{10}$ of 1.6 . This value agrees with that calculated by Webb (1978) for subadult rainbow trout $\left(\mathrm{Q}_{10}=1.8\right.$ between 5 and $25^{\circ} \mathrm{C}$ ). The $\mathrm{Q}_{10}$ for maximum velocity of zebra danio larvae was 1.4. This value is similar to the $\mathrm{Q}_{10}$ of 1.5 for contraction time of the white muscle used in fast starts (Wardle 1975).

Temperature-induced changes in the physical properties of water probably contributed little to the observed responses. Although viscosity changed by about $23 \%$ in the experimental thermal regime (based on values for distilled water), viscous forces would have been a negligible component of total drag throughout a response, according to the hydrodynamic principles discussed by Weihs (1980) and Webb and Weihs (1986). Changes in viscosity would only be important to larvae when $R e$ is less than 20 . This corresponds to velocities below about $5 \mathrm{~mm} / \mathrm{s}$ for the larvae used here. The viscous and

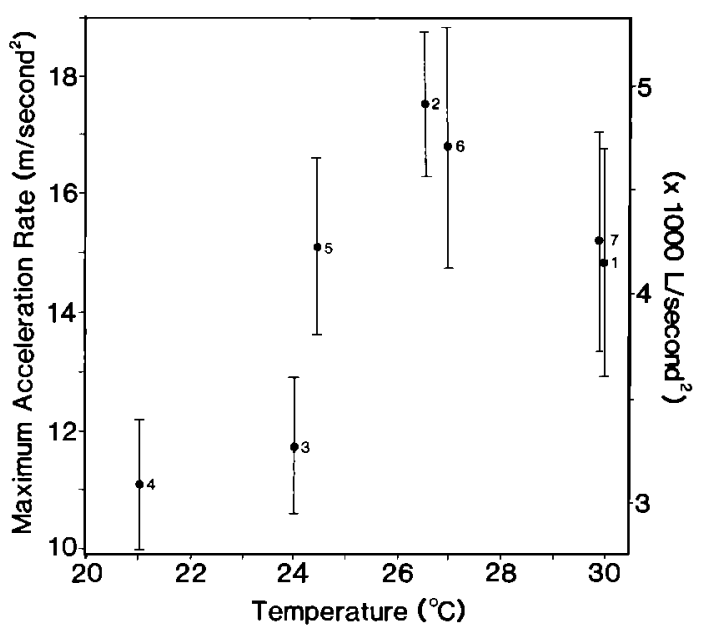

FIGURE 4.-Relationship between maximum acceleration rate of zebra danios (in $\mathrm{mm} / \mathrm{s}^{2}$ and body lengths $\mathrm{L} / \mathrm{s}^{2}$ ) and temperature. Numbers indicate the temporal sequence of responses ( $1-4$, cooling phase; $4-7$, heating phase).

intermediate $(20<R e<200)$ hydrodynamic regimes, where viscosity might still influence movement of larvae, extends to a velocity of about 50 $\mathrm{mm} / \mathrm{s}$. Larvae accelerated so rapidly that they exceeded the limits of the intermediate regime within the first 2 to $6 \mathrm{~ms}$, even at the coldest temperatures (Figure 1). At the end of a response, when larvae coast at low velocities of a few millimeters per second, the influence of viscous drag should halt movement rather abruptly. These few milliseconds at each end of the response represented only a small fraction (about $5 \%$ ) of the duration of a complete burst-swimming event, so a viscosity effect would not be noticeable.

The effects of temperature on burst-swimming performance of larval zebra danios can be compared with data for larger $(136-\mathrm{mm})$ rainbow trout (Webb 1978). Aside from differences in species, size, and temperature range, there is a fundamental difference in the questions addressed by each of these studies and the methods used to obtain the data. The present paper examines temperature effects in an ecological context by imposing a simulated natural fluctuating thermal regime on the larvae. Webb (1978) intended to define the physiological responses to temperature by measuring performance at several constant temperatures. These different approaches do, however, yield results that are comparable on some level.

The nature of the relationship between peak performance measures and temperature was different 
for zebra danio larvae than for larger rainbow trout. Maximum velocity was a linear function of temperature for the zebra danios, but for the trout it increased to a plateau at $15^{\circ} \mathrm{C}$. Webb interpreted the latter data as indicating that maximum velocity (and acceleration) was relatively independent of temperature and "reduced only at low temperatures." Yet, it is the lower range of his experimental temperatures that are commonly experienced by rainbow trout in nature (Scott and Crossman 1973). The higher temperatures approached the upper lethal limit of $24^{\circ} \mathrm{C}$ (Black 1953). The temperature range used in the zebra danio experiments was well within their tolerance zone and was chosen to represent typical daily experiences. Thus, maximum velocity may be linearly related to temperature within usual ecological values.

Maximum acceleration by zebra danios was not linear. At $30^{\circ} \mathrm{C}$, maximum acceleration decreased from the levels at $27^{\circ} \mathrm{C}$. Zebra danios do not spawn readily above $28^{\circ} \mathrm{C}$ (personal observation), perhaps indicating that $30^{\circ} \mathrm{C}$ approaches some stressful level. These acceleration data may represent a plateau similar to that found by Webb for acceleration by rainbow trout. But, the close agreement between the two observations at $27^{\circ} \mathrm{C}$ and at $30^{\circ} \mathrm{C}$ (Figure 4) suggests that this apparent decrease in performance is real.

Burst-swimming performance measurements for larvae of other species are scarce. Pioneers such as Blaxter (1962) and Ryland (1963) obtained maximum velocities slightly in excess of $10 \mathrm{BL} / \mathrm{s}$ by using a stopwatch and measurement grid. These were underestimates because of the low precision inherent in the technique. Zebra danio larvae reach higher size-specific velocities than other larvae reported to date. Webb's and Corolla's (1981) model for maximum velocity of northern anchovy $E n$ graulis mordax at $17^{\circ} \mathrm{C}$ yields an estimate of 94 $\mathrm{mm} / \mathrm{s}(26 \mathrm{BL} / \mathrm{s})$ for a $3.6-\mathrm{mm}$ larva. From the relationship for combined data in Table 1, zebra danio larvae of the same size should reach a maximum velocity of $156 \mathrm{~mm} / \mathrm{s}(43 \mathrm{BL} / \mathrm{s})$ at $17^{\circ} \mathrm{C}$. Little of this difference can be explained by the slower framing rate used by Webb and Corolla $(250 \mathrm{~Hz})$ because the increased precision associated with higher framing rates becomes asymptotic. I calculated maximum (smoothed) velocities for effective framing rates of 200 and $100 \mathrm{~Hz}$ by sampling every second and fourth frame and found that the results were lower than the $400-\mathrm{Hz}$ values by an average of 0.5 and $7.2 \%(0.9$ and $13.7 \mathrm{~mm} / \mathrm{s})$, respectively.
Ecologically, burst-swimming performance is critical to the survival of larval fishes. Webb and Corolla (1981) combined Hunter's (1972) data with their own to show that northern anchovy larvae reach maximum burst velocity while attacking prey. Likewise, burst swimming is the active means by which larvae escape from predators. Larvae cannot match the performance of larger piscine predators but, because fishes seldom pursue their prey (Nyberg 1971; Neill and Cullen 1974; Webb and Skadsen 1980; Webb 1981, 1984), survival of an encounter with a predator depends largely on evading a single strike. Successful evasion would seem to hinge upon the proper timing (measured as response latency and looming threshold), magnitude (distance, velocity, and acceleration), and direction of the response.

Hunter (1976) discussed the importance of determining the ability of predators to capture larvae (or conversely, of larvae to escape) in the context of quantifying larval fish mortality and, ultimately, recruitment and year-class strength. My study determined changes in one aspect of the physiological capacity of larvae to evade predators and capture prey in a thermally fluctuating environment. Direct measurements were not made, but it seems that larvae should be more vulnerable to predators and less effective at capturing elusive prey during the hours around sunrise when water temperature is at its minimum. Best performance should occur near midday. Similar conclusions might be drawn with respect to less predictable temperature fluctuations. Yocom and Edsall (1974) found that the capture-success rate of yearling yellow perch Perca flavescens feeding on larval lake whitefish Coregonus clupeaformis increased with temperature by 1.4 times between 10 and $18^{\circ} \mathrm{C}$ $\left(\mathrm{Q}_{10}=1.8\right)$. Thus, temperature-induced changes in burst performance may translate into real differences in vulnerability to predators. That size affects burst performance (Webb and Corolla 1981) and escape success (Webb 1981) of larvae indicates that future work should follow the ontogeny of burst performance in an effort to identify the size or age beyond which vulnerability to predators changes insignificantly.

\section{Acknowledgments}

I thank Paul W. Webb for his review of the manuscript and his support and advice during this study.

\section{References}

Bamforth, S. S. 1962. Diurnal changes in shallow aquatic habitats. Limnology and Oceanography 7:343-353. 
Batty, R. S. 1981. Locomotion of plaice larvae. Symposia of the Zoological Society of London 48:5369.

Black, E. C. 1953. Upper lethal temperatures of some British Columbia freshwater fishes. Journal of the Fisheries Research Board of Canada 10:196-210.

Blaxter, J. H. S. 1962. Herring rearing. IV. Rearing beyond the yolk-sac stage. Marine Research Department of Agriculture and Fisheries for Scotland 1:1-18.

Blaxter, J. H. S. 1969. Development: eggs and larvae. Pages 177-252 in W. S. Hoar and D. J. Randall, editors. Fish physiology, volume 3. Academic Press, New York.

Blaxter, J. H. S. 1986. Development of sense organs and behaviour of teleost larvae with special reference to feeding and predator avoidance. Transactions of the American Fisheries Society 115:98-114.

Caulton, M. S. 1982. Feeding, metabolism and growth of tilapias: some quantitative considerations. Pages 157-180 in R. S. V. Pullin and R. H. Lowe-McConnell, editors. The biology and culture of tilapias. ICLARM (International Center for Living Aquatic Resources Management) Conference Proceedings 7, Manila.

Eaton, R. C., and R. DiDomenico. 1986. Role of the teleost escape response during development. Transactions of the American Fisheries Society 115:128142.

Eaton, R. C., R. D. Farley, C. B. Kimmel, and E. Schabtach. 1977. Functional development in the Mauthner cell system of embryos and larvae of the zebra fish. Journal of Neurobiology 8:151-172.

Eaton, R. C., and J. Nissanov. 1985. A review of Mauthner-initiated escape behavior and its possible role in hatching in the immature zebrafish, Brachydanio rerio. Environmental Biology of Fishes 12: 265-279.

Elliott, J. M. 1981. Some aspects of thermal stress on freshwater teleosts. Pages $209-245$ in A. D. Pickering, editor. Fish and stress. Academic Press, London.

Hunter, J. R. 1972. Swimming and feeding behavior of larval anchovy, Engraulis mordax. U.S. National Marine Fisheries Service Fishery Bulletin 70:821838.

Hunter, J. R. 1976. Report of a colloquium on larval fish mortality studies and their relation to fishery research, January 1975. NOAA (National Oceanic and Atmospheric Administration) Technical Report, NMFS (National Marine Fisheries Service) Circular 395:1-5.

Jayaram, K. C. 1981. The freshwater fishes of India, Pakistan, Bangladesh, Burma and Sri Lanka-a handbook. Zoological Survey of India, Calcutta.
Laale, H. W. 1977. The biology and use of zebrafish, Brachydanio rerio in fisheries research. A literature review. Journal of Fish Biology 10:121-173.

Neill, S. R. St. J., and J. M. Cullen. 1974. Experiments on whether schooling by their prey affects the hunting behavior of cephalopods and fish predators. Journal of Zoology (London) 172:549-569.

Nyberg, D. W. 1971. Prey capture in the largemouth bass. American Midland Naturalist 86:128-144.

Ryland, J. S. 1963. The swimming speeds of plaice larvae. Journal of Experimental Biology 40:285-299.

Scott, W. B., and E. J. Crossman. 1973. Freshwater fishes of Canada. Fisheries Research Board of Canada Bulletin 184.

Smid, P., and K. Priban. 1978. Microclimate in fishpond littoral ecosystems. Pages 104-1 12 in D. Dykyjova and J. Kvet, editors. Pond littoral ecosystems, structure and functioning. Springer-Verlag, Berlin.

Snedecor, G. W., and W. G. Cochran. 1967. Statistical methods. Iowa State University, Ames.

Wardle, C. S. 1975. Limit of fish swimming speed. Nature (London) 255:725-727.

Webb, P. W. 1978. Effects of temperature on fast-start performance of rainbow trout (Salmo gairdneri). Journal of the Fisheries Research Board of Canada 35:1417-1422.

Webb, P. W. 1981. Responses of northern anchovy, Engraulis mordax, larvae to predation by a biting planktivore, Amphiprion percula. U.S. National Marine Fisheries Service Fishery Bulletin 79:727735.

Webb, P. W. 1984. Chase response latencies of some teleostean piscivores. Comparative Biochemistry and Physiology A, Comparative Physiology 79:45-48.

Webb, P. W., and R. T. Corolla. 1981. Burst swimming performance of northern anchovy, Engraulis mordax, larvae. U.S. National Marine Fisheries Service Fishery Bulletin 79:143-150.

Webb, P. W., and J. M. Skadsen. 1980. Strike tactics of Esox. Canadian Journal of Zoology 58:14621469.

Webb, P. W., and D. Weihs. 1986. Functional locomotor morphology of early life history stages of fishes. Transactions of the American Fisheries Society 115:115-127.

Weihs, D. 1980. Energetic significance of changes in swimming modes during growth of larval anchovy, Engraulis mordax. U.S. National Marine Fisheries Service Fishery Bulletin 77:597-604.

Yocom, T. G., and T. A. Edsall. 1974. Effect of acclimation temperature and heat shock on vulnerability of fry of lake whitefish (Coregonus clupeaformis) to predation. Journal of the Fisheries Research Board of Canada 31:1503-1506. 